\title{
Protective effect of pretreatment with propofol against tumor necrosis factor- $\alpha$-induced hepatic insulin resistance
}

\author{
LONG ZHOU $^{1,2^{*}}$, LILIN WANG ${ }^{3 *}$, BAOCHENG YANG $^{3}$, JINFENG ZENG $^{3}$, \\ QINGGUO ZHANG ${ }^{1}$, HONGYI LEI $^{1}$ and SHIYUAN XU ${ }^{1}$ \\ ${ }^{1}$ Department of Anesthesiology, Zhujiang Hospital, Southern Medical University, Guangzhou, Guangdong 510282; \\ ${ }^{2}$ Department of Medicine, Shenzhen Family Planning Service Center, Shenzhen, Guangdong 518028; \\ ${ }^{3}$ Shenzhen Blood Center, Shenzhen, Guangdong 518035, P.R. China
}

Received August 9, 2014; Accepted May 1, 2015

DOI: $10.3892 /$ etm.2015.2496

\begin{abstract}
Insulin resistance is common in critically ill patients and seriously affects their prognosis. The anesthetic propofol (2,6-diisopropylphenol) has been shown to cause insulin resistance in rats; however, the specific mechanism underlying this phenomenon remains unknown. Thus, the aim of the present study was to determine the molecular mechanism through which propofol influences insulin resistance in the liver. The current study assessed the effects of propofol on the phosphorylation level of key enzymes involved in the insulin signaling pathway, as well as the glycogen content in primary mouse hepatocytes. Propofol administration was demonstrated to considerably reduce the phosphorylation levels of Akt (Ser473) and glycogen synthase kinase (GSK)-3 $\beta$ (Ser9) in the primary mouse hepatocytes. In addition, propofol was shown to downregulate the phosphoinositide 3-kinase (PI3K)/Akt/GSK-3 $\beta$ signaling pathway and inhibit glycogen synthesis in hepatocytes. Thus, the present results indicated that propofol induced insulin resistance in primary mouse hepatocytes. Notably, pretreatment with propofol in tumor necrosis factor (TNF)- $\alpha$-induced primary mouse hepatocytes with insulin resistance was demonstrated to alleviate the inhibitory effects of TNF- $\alpha$ on the PI3K/Akt/GSK-3 $\beta$ signaling pathway and glycogen synthesis. These results indicated that propofol exerts a protective effect against insulin resistance in primary mouse hepatocytes induced by TNF- $\alpha$, indicating that
\end{abstract}

Correspondence to: Professor Shiyuan Xu, Department of Anesthesiology, Zhujiang Hospital, Southern Medical University, 1,838 Guangzhou Avenue North, Guangzhou, Guangdong 510282, P.R. China

E-mail: xushiyuan355@189.cn

${ }^{*}$ Contributed equally

Key words: propofol, insulin resistance, mouse primary hepatocytes, glycogen, protein kinase $\mathrm{B}$, glycogen synthase kinase- $3 \beta$ propofol therapy may be clinically feasible to alleviate insulin resistance in critically ill patients.

\section{Introduction}

Insulin resistance is the primary mechanism underlying hyperglycemia in critically ill patients (1-4). Insulin resistance and the resulting hyperglycemia seriously influence the prognosis of critical patients, aggravating the disease and increasing the risk of complications and mortality (5-8). Propofol (2,6-diisopropylphenol) is the most common intravenous anesthetic agent used to narcotize or mitigate pain in critically ill patients. Recently, Yasuda et al (9) investigated the effects of propofol on insulin sensitivity in rats. The results revealed that anesthesia with propofol induced systemic insulin resistance through decreasing insulin-stimulated glucose uptake in the skeletal and heart muscle, and attenuating the insulin-mediated suppression of hepatic glucose output.

However, little information is available with regard to the effect of propofol alone on the insulin signaling pathway and insulin resistance, excluding the effects of other factors, such as surgical stress and the presence of fat-soluble carriers. Thus, whether propofol aggravates insulin resistance in critically ill patients and whether the infusion of propofol is safe in critical patients with insulin resistance remain unknown.

The liver is the major target organ of insulin, and the most important organ involved in the regulation of glucolipid metabolism (10). In the present study, the effects of propofol on insulin resistance in primary mouse hepatocytes were examined with the aim to investigate the molecular mechanisms underlying the effect of propofol on insulin resistance.

The research results may provide a scientific basis for the targeted prevention and treatment of insulin resistance in critically ill patients, and guide the selection of appropriate anesthetic methods and drugs clinically.

\section{Materials and methods}

Reagents. Clinical propofol injections contain numerous auxiliary materials, including fats, soybean oils, purified lecithin, glycerin and oleic acid, and high fat can induce 
insulin resistance (11-13). In order to avoid the interference of auxiliary materials in the propofol injection, propofol with a high purity (97\%; Sigma-Aldrich, St. Louis, MO, USA) was selected. Due to the hydrophobicity of propofol, $0.1 \%$ (final concentration) dimethyl sulfoxide (DMSO) was used as a solvent. Lithium chloride $(\mathrm{LiCl})$ was used in the experiment to determine whether GSK-3 $\beta$ is a target of propofol. $\mathrm{LiCl}$, tumor necrosis factor (TNF)- $\alpha$ and DMSO were purchased from Sigma-Aldrich. TNF- $\alpha$ was used to induce insulin resistance in primary mouse hepatocytes (14-16). The culture reagents were purchased from Invitrogen Life Technologies (Carlsbad, CA, USA), and the reagents used for SDS-PAGE were obtained from Bio-Rad Laboratories, Inc. (Hercules, CA, USA). Antibodies against Akt, phosphorylated (p) Akt (Ser473), glycogen synthase kinase-3 $\beta$ (GSK-3 $\beta$ ) and p-GSK-3 $\beta$ (Ser9) were purchased from Cell Signaling Technology, Inc. (Danvers, MA, USA).

Animals. A total of 10 male C57BL/6J mice (age, 8 weeks; weight, 22-32 g) were provided by Peking University Health Science Center (Beijing, China). A single mouse provided between $5 \times 10^{7}$ and $5 \times 10^{8}$ primary hepatocytes. Animal procedures were performed in accordance with the National Institutes of Health Animal Care and Use Guidelines (17), and animal experimental protocols were approved by the Animal Ethics Committee of Zhujiang Hospital (Guangzhou, China).

Isolation of mouse primary hepatocytes. Primary hepatocytes were isolated using a two-step collagenase perfusion method [0.2 $\mathrm{mg} / \mathrm{ml}$ type IV collagenase (Sigma-Aldrich) in Hank's balanced salt solution], as described previously $(18,19)$. The hepatocytes were collected by centrifugation at $120 \mathrm{x} \mathrm{g}$ for $8 \mathrm{~min}$. Immediately following harvesting, the cells were suspended in prewarmed William's E medium (Sigma-Aldrich) that was supplemented with $10 \%$ fetal bovine serum, $20 \mathrm{ng} / \mathrm{ml}$ dexamethasone (Sigma-Aldrich), insulin (5 mg/l), transferrin (5 mg/l), sodium selenate (5 $\mu \mathrm{g} / \mathrm{l}$; Sigma-Aldrich) and $10 \mu \mathrm{g} / \mathrm{ml}$ gentamicin (Invitrogen Life Technologies). The hepatocytes were plated in collagen-coated $25-\mathrm{cm}^{2}$ flasks at a density of $1 \times 10^{6}$ cells/flask and would be used as a control in the following experiment.

Western blot analysis. Cell lysates (15-30 $\mu \mathrm{g}$ protein) were separated by $10 \%$ SDS-PAGE and transferred to polyvinyldifluoride membranes (Millipore Corporation, Billerica, MA, USA), after which the membranes were blocked with 5\% nonfat dry milk. Subsequently, the membranes were probed with antibodies against Akt, p-Akt, GSK and p-GSK at $4^{\circ} \mathrm{C}$ overnight. The blots were also probed with a $\beta$-actin antibody to ensure that approximately equal amounts of protein were loaded. Next, the blots were incubated with a horseradish peroxidase-conjugated anti-IgG secondary antibody, which was followed by detection with enhanced chemiluminescence (Millipore Corporation).

Analysis of the glycogen content. Glycogen levels were measured in the cells for $3 \mathrm{~h}$ in the presence of $10 \mathrm{nmol} / \mathrm{l}$ insulin (USBio, Salem, MA, USA) using a glycogen assay kit (Biovision, Inc., Milpitas, CA, USA).
Cell viability assay. A 3-(4,5-dimethylthiazol-2-yl)-2,5-diphenyltetrazolium bromide tetrazole (MTT) reduction assay was used to asses cell viability. Mouse primary hepatocytes were plated in 24-well plates ( $3 \times 10^{4}$ cells per well). After incubation for $24 \mathrm{~h}$, the cells were treated with increasing concentrations of propofol for $24 \mathrm{~h}$. MTT $(0.5 \mathrm{mg} / \mathrm{ml}$; Sigma-Aldrich) was then added to each well $(200 \mu \mathrm{l} /$ well $)$. After additional incubation for $4 \mathrm{~h}$, MTT solution was discarded and $200 \mu \mathrm{l}$ DMSO (Amresco LLC, Solon, OH, USA) was added and the plates were shaken gently. The absorbance was measured using an ELISA reader at a wavelength of $490 \mathrm{~nm}$.

Statistical analysis. Data represent the mean of duplicate samples from three separately performed experiments, and the results are expressed as the mean \pm standard deviation. Statistical analysis was performed with SPSS statistical software (version 19.0; IBM SPSS, Armonk, NY, USA). Differences between two groups were analyzed for statistical significance using the Student's $t$-test, while one-way analysis of variance, followed by Tukey's test, were used to compare the differences among $>2$ groups. $\mathrm{P}<0.05$ was considered to indicate a statistically significant difference.

\section{Results}

Effects of propofol on the cell viability of mouse primary hepatocytes. Cell viability of the primary mouse hepatocytes was detected with a MTT assay, subsequent to the hepatocytes being treated with different concentrations of propofol for $24 \mathrm{~h}$. Propofol at concentrations between 1 and $25 \mu \mathrm{g} / \mathrm{ml}$ was shown to have no significant effect on the cell viability (Fig. 1A); however, when the final concentration of propofol reached $100 \mu \mathrm{g} / \mathrm{ml}$, the cell viability decreased to $35 \pm 5 \%$ of the control $(\mathrm{P}<0.001)$. Thus, a $10-\mu \mathrm{g} / \mathrm{ml}$ concentration of propofol was selected to use in the subsequent experiments, since minimal effects were observed on the cell viability compared with higher doses, and use of this concentration had been previously reported $(20,21)$. In the following experiment, the effect of propofol at different culture periods (1-32 h) was analyzed. The results revealed no statistically significant differences in the viability of the hepatocytes following treatment with $10 \mu \mathrm{g} / \mathrm{ml}$ propofol between 1 and $32 \mathrm{~h}(\mathrm{P}>0.05$; Fig. 1B). From these results, the dose of propofol selected was demonstrated to not affect the viability of the hepatocyptes during the culture period of the subsequent assays.

Propofol induces insulin resistance in mouse primary hepatocytes. Primary mouse hepatocytes were treated with $10 \mu \mathrm{g} / \mathrm{ml}$ propofol for $24 \mathrm{~h}$, after which the cells were assayed with western blot analyses to detect the protein expression levels of components of the phosphoinositide 3-kinase (PI3K)/Akt/GSK-3 $\beta$ signaling pathway. In addition, a glycogen assay kit was used to detect the level of glycogen synthesis. Following treatment with propofol for $24 \mathrm{~h}$, the phosphorylation levels of Akt (Ser473) and GSK-3 $\beta$ (Ser9) were found to decrease (Fig. 2A-C), and the rate of glycogen synthesis had reduced (Fig. 2D). Hepatocytes were simultaneously treated with propofol (final concentration, $10 \mu \mathrm{g} / \mathrm{ml}$ ) and $\mathrm{LiCl}$ (final concentration, $20 \mu \mathrm{mol} / \mathrm{l}$ ) for $24 \mathrm{~h}$. No statistically significant difference was observed in the level of glycogen synthesis or the ratio of pGSK-3 $\beta$ (Ser9)/GSK-3 $\beta$ 

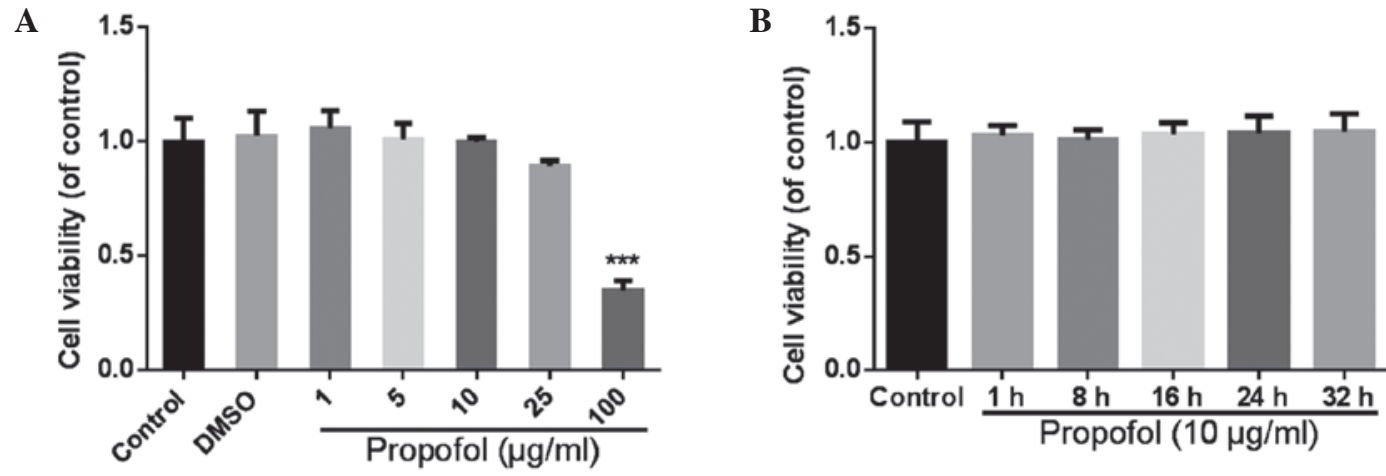

Figure 1. Effect of propofol on the cell viability of mouse primary hepatocytes. (A) Mouse primary hepatocyte viability was not significantly affected by treatment with the tested propofol concentrations $(1-25 \mu \mathrm{g} / \mathrm{ml})$, although cell viability was impaired at concentrations over the tested concentration range $(>100 \mu \mathrm{g} / \mathrm{ml})$. ${ }^{* * *} \mathrm{P}<0.001$, vs. DMSO group. (B) Mouse primary hepatocyte viability was not significantly affected by treatment with propofol (10 $\left.\mu \mathrm{g} / \mathrm{ml}\right)$ for 32 h. DMSO, dimethyl sulfoxide.

A

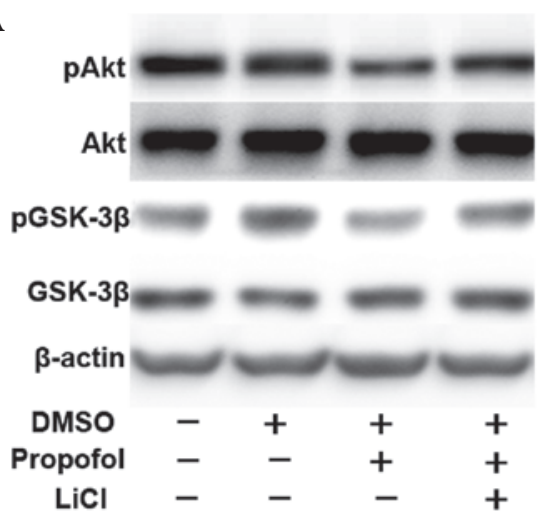

C

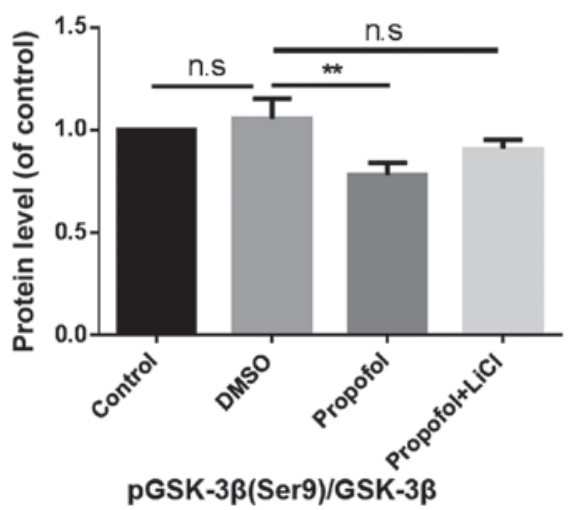

B

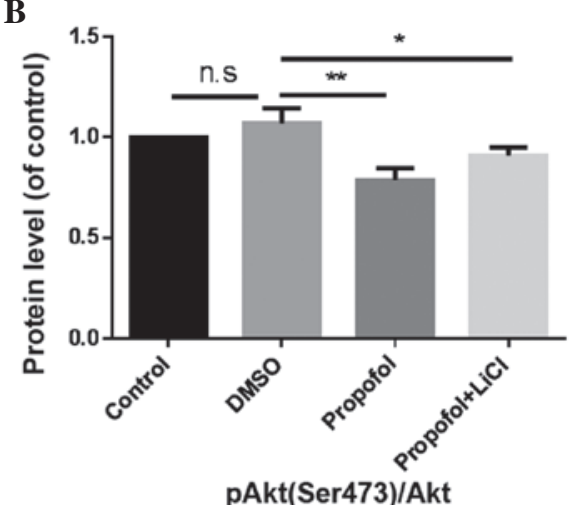

D

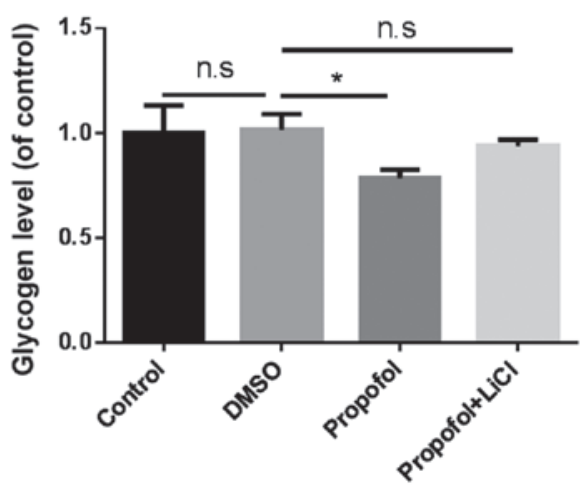

Figure 2. (A) Western blot analysis showing the protein expression levels of pAkt (Ser473), Akt, pGSK-3 $\beta$ (Ser9) and GSK-3 $\beta$, where $\beta$-actin was used as an internal control. (B) Propofol inhibits pAkt (Ser473)/Akt expression in mouse primary hepatocytes. ${ }^{* *} \mathrm{P}<0.01$, propofol vs. DMSO group; ${ }^{*} \mathrm{P}<0.05$, propofol + LiCl vs. DMSO group. (C) Propofol inhibits pGSK-3 $\beta$ (Ser9)/GSK-3 $\beta$ expression in mouse primary hepatocytes. ${ }^{* *} \mathrm{P}<0.01$, propofol vs. DMSO group. (D) Glycogen levels were measured in mouse primary hepatocytes using a glycogen assay kit. Propofol inhibits glycogen synthesis in mouse primary hepatocytes. "P<0.05, propofol vs. DMSO group. LiCl, lithium chloride; DMSO, dimethylsulfoxide; GSK, glycogen synthase kinase; n.s., not significant.

between the propofol $+\mathrm{LiCl}$ and DMSO groups $(\mathrm{P}>0.05)$. However, a statistically significant difference was observed in the ratio of pAkt (Ser473)/Akt between the propofol $+\mathrm{LiCl}$ and DMSO groups $(\mathrm{P}<0.05)$, and a statistically significant difference was observed in the ratio of pAkt (Ser473)/Akt between the propofol $+\mathrm{LiCl}$ and propofol groups $(\mathrm{P}<0.05)$. Furthermore, a statistically significant difference was observed between pAkt (Ser473) and Akt expression levels, as well as between propofol alone and propofol $+\mathrm{LiCl}(\mathrm{P}<0.05)$.
TNF- $\alpha$ inhibits the PI3K/Akt/GSK-3 $\beta$ signaling pathway and glycogen synthesis in mouse primary hepatocytes. Following treatment with TNF- $\alpha$ for $24 \mathrm{~h}$, the expression levels of pAkt (Ser473)/Akt decreased to $45 \pm 12 \%$ of that in the control group $(\mathrm{P}<0.01)$, while the pGSK-3 $\beta$ (Ser9)/GSK-3 $\beta$ expression levels decreased to $47 \pm 11 \%$ of that in the control group $(\mathrm{P}<0.01)$. In addition, the level of glycogen synthesis declined to $49 \pm 10 \%$ of that in the control group $(\mathrm{P}<0.01$; Fig. 3$)$. Therefore, TNF- $\alpha$ was shown to mimic the effects of propofol. 
A

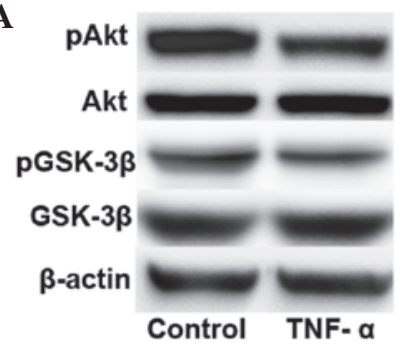

B

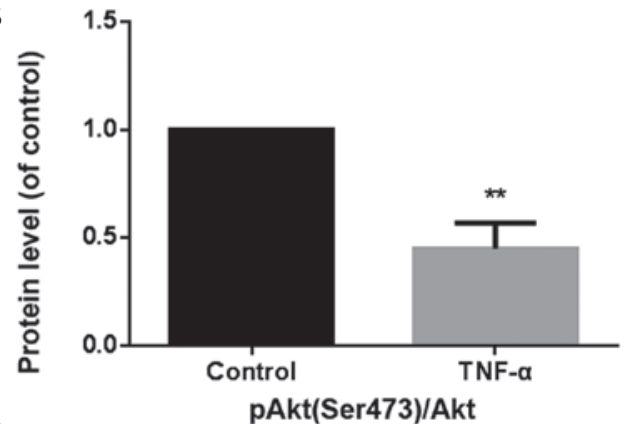

C

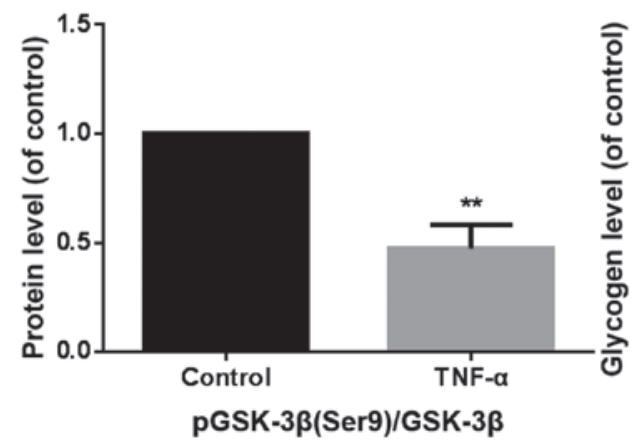

D

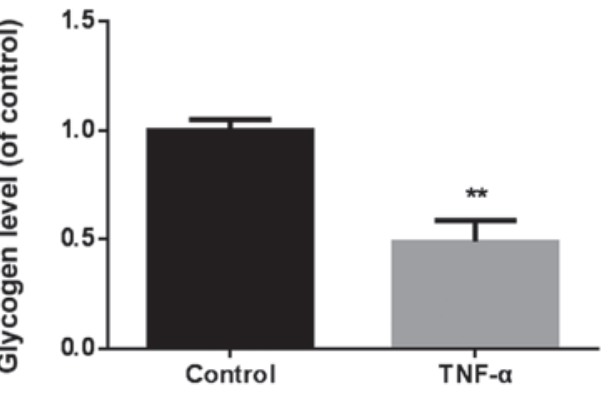

Figure 3. TNF- $\alpha$ inhibits the PI3K/Akt/GSK-3 $\beta$ signaling pathway and glycogen synthesis in mouse primary hepatocytes. (A) Western blot analysis showing the protein expression levels of pAkt (Ser473), Akt, pGSK-3 $\beta$ (Ser9) and GSK-3 $\beta$, where $\beta$-actin was used as an internal control. (B) TNF- $\alpha$ inhibits pAkt (Ser473)/Akt expression in mouse primary hepatocytes. ${ }^{* *} \mathrm{P}<0.01$, vs. control. (C) TNF- $\alpha$ inhibits pGSK-3 $\beta$ (Ser9)/GSK-3 $\beta$ expression in mouse primary hepatocytes. ${ }^{* *} \mathrm{P}<0.01$, vs. control. (D) Glycogen levels were measured in mouse primary hepatocytes using a glycogen assay kit. TNF- $\alpha$ inhibits glycogen synthesis in mouse primary hepatocytes. ${ }^{* *} \mathrm{P}<0.01$, vs. control. TNF, tumor necrosis factor; PI3K, phosphoinositide 3-kinase; GSK, glycogen synthase kinase.

A

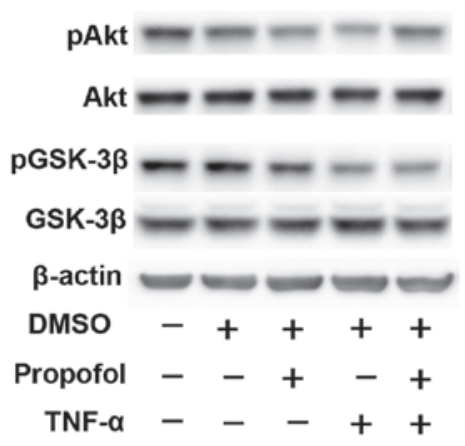

C

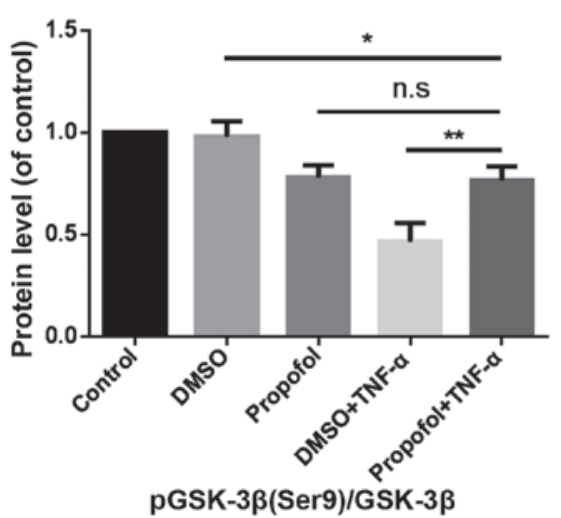

B

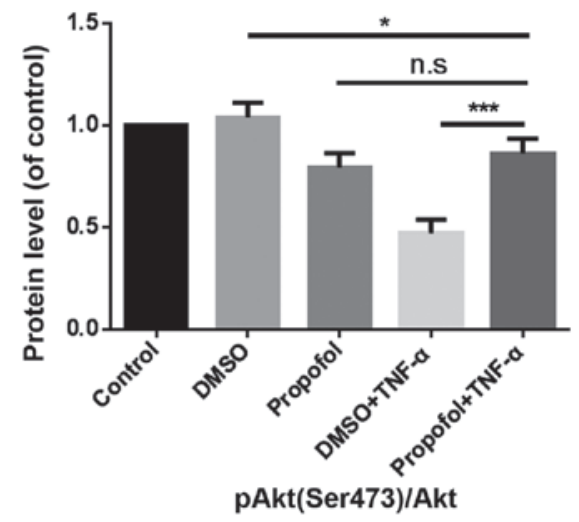

D

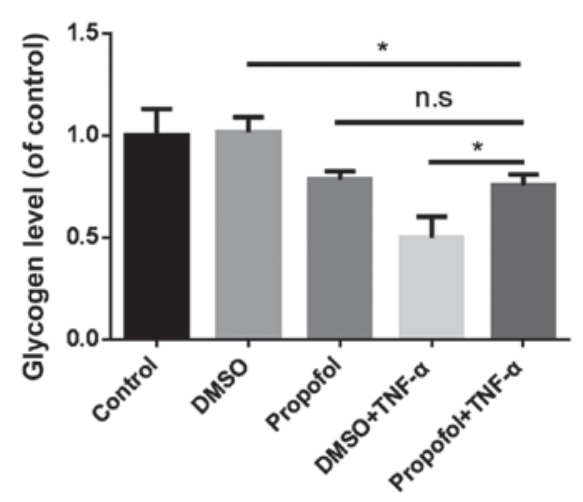

Figure 4. Pretreatment with propofol alleviates the inhibition of TNF- $\alpha$ on the PI3K/Akt/GSK-3 $\beta$ signaling pathway and glycogen synthesis in mouse primary

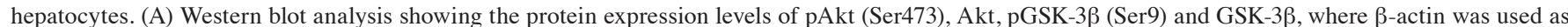
an internal control. (B) Effect of the different treatments on pAkt (Ser473)/Akt protein expression levels. ${ }^{* * *} \mathrm{P}<0.001$, propofol + TNF- $\alpha$ vs. DMSO + TNF- $\alpha$ groups. (C) Effect of the different treatments on pGSK-3 $\beta$ (Ser9)/GSK-3 $\beta$ protein expression levels. ${ }^{* *} \mathrm{P}<0.01$, propofol + TNF- $\alpha$ group vs. DMSO + TNF- $\alpha$ group. (D) Glycogen levels were measured in mouse primary hepatocytes using a glycogen assay kit. "P<0.05, propofol + TNF- $\alpha$ group vs. DMSO + TNF- $\alpha$ group. TNF, tumor necrosis factor; PI3K, phosphoinositide 3-kinase; GSK, glycogen synthase kinase; DMSO, dimethylsulfoxide; n.s., not significant. 
Pretreatment with propofol alleviates the inhibition of TNF- $\alpha$ on the PI3K/Akt/GSK-3 $\beta$ signaling pathway and glycogen synthesis in mouse primary hepatocytes. Hepatocytes were treated with $10 \mu \mathrm{g} / \mathrm{ml}$ propofol for $6 \mathrm{~h}$, and subsequently treated with $10 \mathrm{ng} / \mathrm{ml}$ TNF- $\alpha$ for $24 \mathrm{~h}$. The results revealed that the expression levels of pAkt (Ser473)/Akt and pGSK-3 $\beta$ (Ser9)/GSK-3 $\beta$, and the glycogen content in the propofol pretreatment group, were higher compared with those in the DMSO + TNF- $\alpha$ group $(\mathrm{P}<0.001, \mathrm{P}<0.01$ and $\mathrm{P}<0.05$, respectively; Fig. 4).

\section{Discussion}

Insulin resistance is a physiological state that is characterized by the failure to suppress glycogenolysis or hepatic glucose production (22). The blockage or weakening of insulin signal transduction, which can be induced by multiple factors, is the main pathogenetic mechanism underlying insulin resistance (23). The PI3K-Akt signaling pathway is a classic insulin signal transduction pathway (24), and all the factors that directly or indirectly influence this pathway are able to induce insulin resistance. In the present study, propofol was demonstrated to significantly reduce the phosphorylation levels of Akt (Ser473) and GSK-3ß (Ser9), which subsequently blocked the PI3K/Akt/GSK-3 $\beta$ signaling pathway and inhibited glycogen synthesis in primary mouse hepatocytes. These results indicated that propofol induced insulin resistance in primary mouse hepatocytes.

Lithium selectively inhibits GSK-3 $\beta$ activity $(25,26)$. As shown in Fig. 2, there were no statistically significant differences in the glycogen synthesis level $(\mathrm{P}>0.05)$ or the GSK-3 $\beta$ (Ser9) phosphorylation level $(\mathrm{P}>0.05)$ when comparing the group treated with propofol and lithium and the control group. However, the phosphorylation level of Akt (Ser473) was significantly different $(\mathrm{P}<0.05)$ between the two groups. These results indicate that $\mathrm{LiCl}$ counteracts the inhibitory effect of propofol on glycogen synthesis in primary mouse hepatocytes. In addition, the results demonstrate that the inhibition of GSK-3 $\beta$ (Ser9) phosphorylation is a critical step in the inhibitory effect of propofol on glycogen synthesis in primary mouse hepatocytes. However, $\mathrm{LiCl}$ was unable to completely eliminate the inhibitory effect of propofol on the PI3K/Akt/GSK-3 $\beta$ signaling pathway, indicating that the target of propofol for the induction of insulin resistance in primary mouse hepatocytes was upstream of GSK-3 $\beta$.

TNF- $\alpha$, which is mainly secreted by monocytes or macrophages, is an important proinflammatory cytokine, and also a key component in obesity and insulin resistance $(27,28)$. In the present study, TNF- $\alpha$ was shown to inhibit the PI3K/Akt/GSK-3 $\beta$ signaling pathway and glycogen synthesis in primary mouse hepatocytes. Furthermore, TNF- $\alpha$ induced insulin resistance in the primary mouse hepatocytes. By this means, the cell model of insulin resistance was successfully constructed.

As shown in Fig. 4, the phosphorylation levels of Akt (Ser473) and GSK-3 $\beta$ (Ser9), as well as the total level of glycogen synthesized, in the group treated with propofol and TNF- $\alpha$ were higher compared with the control group treated with TNF- $\alpha$ alone. These observations indicated that pretreatment with propofol alleviated the inhibitory effects of TNF- $\alpha$ on the PI3K/Akt/GSK-3 $\beta$ signaling pathway and glycogen synthesis in primary mouse hepatocytes. Furthermore, the present results indicated that propofol exerted a protective effect on the insulin resistance of primary mouse hepatocytes induced by TNF- $\alpha$. Propofol administration alone was shown to inhibit the PI3K/Akt/GSK-3 $\beta$ signaling pathway in primary mouse hepatocytes. Notably, pretreatment with propofol was also shown to alleviate the inhibition of TNF- $\alpha$ on the PI3K/Akt/GSK-3 $\beta$ signaling pathway in primary mouse hepatocytes. These two seemingly contradictory results indicate that the protective effect of propofol on TNF- $\alpha$-induced insulin resistance in primary mouse hepatocytes is not achieved through a direct effect on the PI3K-Akt signaling pathway.

Nuclear factor $-\kappa \mathrm{B}(\mathrm{NF}-\kappa \mathrm{B})$ is widely distributed in tissue cells (29). The transcription factor plays an important role in cell signal transduction and gene expression regulation, and is also the critical nuclear factor involved in the initiation and regulation of inflammation. In recent years, the inflammatory response mediated by $\mathrm{NF}-\kappa \mathrm{B}$ is one focus of research into the mechanisms underlying insulin resistance $(30,31)$. Following $\mathrm{NF}-\kappa \mathrm{B}$ activation, the transcription of inflammatory factors, such as TNF- $\alpha$, interleukin (IL)- $1 \beta$ and IL- 6 , is initiated and regulated. These transcription factors serve as new activators of NF- $\kappa \mathrm{B}$, and subsequently, a positive feedback loop of low inflammation signaling is formed. As a result, insulin resistance is generated or aggravated $(29,32,33)$. Previous studies have demonstrated that propofol inhibits NF- $\kappa \mathrm{B}$ activity in various tissues or cells (34-38). Therefore, it was hypothesized that the protective effect of propofol against TNF- $\alpha$-induced insulin resistance in primary mouse hepatocytes may be associated with the inhibitory effect of propofol on the NF- $\kappa \mathrm{B}$ signaling pathway.

In conclusion, propofol was demonstrated to induce insulin resistance in primary mouse hepatocytes, while pretreatment with propofol was shown to alleviate insulin resistance in primary mouse hepatocytes induced by TNF- $\alpha$. These results indicate that propofol may alleviate insulin resistance in critically ill patients; thus, the infusion of propofol in critically ill patients may be clinically feasible.

\section{Acknowledgements}

This study was supported by grants from Shenzhen Science and Technology Innovation Committee Project (no. JCYJ20140403093211510) and Shenzhen Health and Family Planning Commission Project (no. 201401074).

\section{References}

1. Fahy BG, Sheehy AM and Coursin DB: Glucose control in the intensive care unit. Crit Care Med 37: 1769-1776, 2009.

2. Gauglitz GG, Herndon DN and Jeschke MG: Insulin resistance postburn: Underlying mechanisms and current therapeutic strategies. J Burn Care Res 29: 683-694, 2008.

3. Lipshutz AK and Gropper MA: Perioperative glycemic control: An evidence-based review. Anesthesiology 110: 408-421, 2009.

4. Coursin DB, Connery LE and Ketzler JT: Perioperative diabetic and hyperglycemic management issues. Crit Care Med 32 (Suppl): S116-S125, 2004.

5. van den Berghe G, Wouters $P$, Weekers F, et al: Intensive insulin therapy in critically ill patients. N Engl J Med 345: 1359-1367, 2001.

6. Krinsley JS: Association between hyperglycemia and increased hospital mortality in a heterogeneous population of critically ill patients. Mayo Clin Proc 78: 1471-1478, 2003. 
7. Laird AM, Miller PR, Kilgo PD, Meredith JW and Chang MC Relationship of early hyperglycemia to mortality in trauma patients. J Trauma 56: 1058-1062, 2004.

8. Deedwania P, Kosiborod M, Barrett E, Ceriello A, Isley W, Mazzone $\mathrm{T}$ and Raskin P; American Heart Association Diabetes Committee of the Council on Nutrition, Physical Activity, and Metabolism: Hyperglycemia and acute coronary syndrome: A scientific statement from the American Heart Association Diabetes Committee of the Council on Nutrition, Physical Activity, and Metabolism. Circulation 117: 1610-1619, 2008.

9. Yasuda Y, Fukushima Y, Kaneki M and Martyn JA: Anesthesia with propofol induces insulin resistance systemically in skeletal and cardiac muscles and liver of rats. Biochem Biophys Res Commun 431: 81-85, 2013.

10. Felig P and Wahren J: Influence of endogenous insulin secretion on splanchnic glucose and amino acid metabolism in man. J Clin Invest 50: 1702-1711, 1971

11. Pehmøller C, Brandt N, Birk JB, et al: Exercise alleviates lipid-induced insulin resistance in human skeletal muscle-signaling interaction at the level of TBC1 domain family member 4. Diabetes 61: 2743-2752, 2012.

12. Schenk S and Horowitz JF: Acute exercise increases triglyceride synthesis in skeletal muscle and prevents fatty acid-induced insulin resistance. J Clin Invest 117: 1690-1698, 2007.

13. Boden G, Lebed B, Schatz M, Homko C and Lemieux S: Effects of acute changes of plasma free fatty acids on intramyocellular fat content and insulin resistance in healthy subjects. Diabetes 50: 1612-1617, 2001

14. Bastard JP, Maachi M, Lagathu C, Kim MJ, Caron M, Vidal H, Capeau $\mathbf{J}$ and Feve B: Recent advances in the relationship between obesity, inflammation and insulin resistance. Eur Cytokine Netw 17: 4-12, 2006.

15. Xu J, Kim HT, Ma Y, Zhao L, Zhai L, Kokorina N, Wang P and Messina JL: Trauma and hemorrhage-induced acute hepatic insulin resistance: Dominant role of tumor necrosis factor- $\alpha$. Endocrinology 149: 2369-2382, 2008.

16. Plomgaard P, Nielsen AR, Fischer CP, Mortensen OH, Broholm C Penkowa M, Krogh-Madsen R, Erikstrup C, Lindegaard B, Petersen AM, et al: Associations between insulin resistance and TNF-alpha in plasma, skeletal muscle and adipose tissue in humans with and without type 2 diabetes. Diabetologia 50 2562-2571, 2007

17. Shi XP, Zong A, Tao J and Wang L: Study of instructive notions with respect to caring for laboratory animals. Zhong Guo Yi Ke Da Xue Xue 36: 493-493, 2007 (In Chinese).

18. Seglen PO: Preparation of isolated rat liver cells. Methods Cell Biol 13: 29-83, 1976.

19. Casciano DA: Development and utilization of primary hepatocyte culture systems to evaluate metabolism, DNA binding, and DNA repair of xenobiotics. Drug Metab Rev 32: 1-13, 2000

20. Smith C, McEwan AI, Jhaveri R, et al: The interaction of fentanyl on the Cp50 of propofol for loss of consciousness and skin incision. Anesthesiology 81: 820-828; discussion 26A, 1994.

21. Hsing $\mathrm{CH}$, Chen $\mathrm{YH}$, Chen $\mathrm{CL}$, et al: Anesthetic propofol causes glycogen synthase kinase-3 $\beta$-regulated lysosomal/mitochondrial apoptosis in macrophages. Anesthesiology 116: 868-881, 2012.
22. Muniyappa R, Lee S, Chen H and Quon MJ: Current approaches for assessing insulin sensitivity and resistance in vivo: Advantages, limitations, and appropriate usage. Am J Physiol Endocrinol Metab 294: E15-E26, 2008.

23. Morino S, Kondo T, Sasaki K, et al: Mild electrical stimulation with heat shock ameliorates insulin resistance via enhanced insulin signaling. PLoS One 3: e4068, 2008.

24. Liu P, Cheng H, Roberts TM and Zhao JJ: Targeting the phosphoinositide 3-kinase pathway in cancer. Nat Rev Drug Discov 8 : 627-644, 2009.

25. Hong M, Chen DC, Klein PS and Lee VM: Lithium reduces tau phosphorylation by inhibition of glycogen synthase kinase-3. J Biol Chem 272: 25326-25332, 1997.

26. Ryves WJ and Harwood AJ: Lithium inhibits glycogen synthase kinase- 3 by competition for magnesium. Biochem Biophys Res Commun 280: 720-725, 2001.

27. Hotamisligil GS: Inflammatory pathways and insulin action. Int J Obes Relat Metab Disord 27 (Suppl 3): S53-S55, 2003.

28. Stephens JM, Lee J and Pilch PF: Tumor necrosis factor-alpha-induced insulin resistance in 3T3-L1 adipocytes is accompanied by a loss of insulin receptor substrate- 1 and GLUT4 expression without a loss of insulin receptor-mediated signal transduction. J Biol Chem 272: 971-976, 1997.

29. Baeuerle PA and Baltimore D: NF-kappa B: Ten years after. Cell 87: 13-20, 1996.

30. Li Y, Yan H, Zhang Z, Zhang G, Sun Y, Yu P, Wang Y and Xu L: Andrographolide derivative AL-1 improves insulin resistance through down-regulation of $\mathrm{NF}-\kappa \mathrm{B}$ signalling pathway. $\mathrm{Br}$ J Pharmacol 2015 (Epub ahead of print).

31. Zhou MS, Liu C, Tian R, Nishiyama A and Raij L: Skeletal muscle insulin resistance in salt-sensitive hypertension: Role of angiotensin II activation of NF- $\kappa$ B. Cardiovasc Diabetol 14: 45 , 2015.

32. Tak PP and Firestein GS: NF- $\kappa$ B: A key role in inflammatory diseases. J Clin Invest 107: 7-11, 2001

33. Gao Z, Hwang D, Bataille F, Lefevre M, York D, Quon MJ and Ye J: Serine phosphorylation of insulin receptor substrate 1 by inhibitor kappa B kinase complex. J Biol Chem 277: 48115-48121, 2002.

34. Du QH, Xu YB, Zhang MY, Yun P and He CY: Propofol induces apoptosis and increases gemcitabine sensitivity in pancreatic cancer cells in vitro by inhibition of nuclear factor- $\kappa \mathrm{B}$ activity. World J Gastroenterol 19: 5485-5492, 2013.

35. Ye HH, Wu KJ, Fei SJ, Zhang XW, Liu HX, Zhang JL and Zhang YM: Propofol participates in gastric mucosal protection through inhibiting the Toll-like receptor-4/nuclear factor kappa-B signaling pathway. Clin Res Hepatol Gastroenterol 37: e3-e15, 2013

36. Li Q, Zhang L, Han Y, Jiang Z and Wang Q: Propofol reduces MMPs expression by inhibiting NF- $\kappa \mathrm{B}$ activity in human MDA-MB-231 cells. Biomed Pharmacother 66: 52-56, 2012.

37. Hsing $\mathrm{CH}$, Lin MC, Choi PC, et al: Anesthetic propofol reduces endotoxic inflammation by inhibiting reactive oxygen species-regulated Akt/IKKbeta/NF- $\mathrm{BB}$ signaling. PLoS One 6: e17598, 2011.

38. Li H, Tan J, Zou Z, Huang CG and Shi XY: Propofol post-conditioning protects against cardiomyocyte apoptosis in hypoxia/reoxygenation injury by suppressing nuclear factor-kappa B translocation via extracellular signal-regulated kinase mitogen-activated protein kinase pathway. Eur J Anaesthesiol 28: 525-534, 2011. 